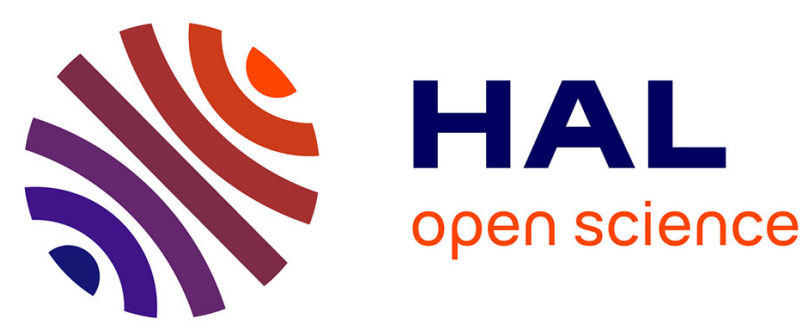

\title{
Fe- $\mathrm{x}$ Ga-(1-x)BO-3 single crystals: synthesis and characterization
}

\author{
S. Yagupov, M. Strugatsky, K. Seleznyova, E. Maksimova, I. Nauhatsky, V. \\ Yagupov, E. Milyukova, Janis Kliava
}

\section{- To cite this version:}

S. Yagupov, M. Strugatsky, K. Seleznyova, E. Maksimova, I. Nauhatsky, et al.. Fe-x Ga-(1-x)BO-3 single crystals: synthesis and characterization. Applied physics. A, Materials science \& processing, 2015, 121 (1), pp.179-185. 10.1007/s00339-015-9404-9 . hal-01216442

\section{HAL Id: hal-01216442 \\ https://hal.science/hal-01216442}

Submitted on 16 Oct 2015

HAL is a multi-disciplinary open access archive for the deposit and dissemination of scientific research documents, whether they are published or not. The documents may come from teaching and research institutions in France or abroad, or from public or private research centers.
L'archive ouverte pluridisciplinaire HAL, est destinée au dépôt et à la diffusion de documents scientifiques de niveau recherche, publiés ou non, émanant des établissements d'enseignement et de recherche français ou étrangers, des laboratoires publics ou privés.

\section{다(1)(2)}

Distributed under a Creative Commons Attribution - ShareAlikel 4.0 International 


\title{
$\mathrm{Fe}_{x} \mathrm{Ga}_{1-x} \mathrm{BO}_{3}$ single crystals: synthesis and characterization
}

\author{
S. Yagupov ${ }^{1} \cdot$ M. Strugatsky $^{1} \cdot$ K. Seleznyova ${ }^{1,2} \cdot$ E. Maksimova $^{1}$. $^{2}$

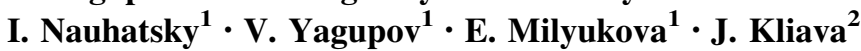

\begin{abstract}
A series of $\mathrm{Fe}_{x} \mathrm{Ga}_{1-x} \mathrm{BO}_{3}$ single crystals in the concentration range $0 \leq x \leq 1$ has been synthesized by solution in the melt method. In order to determine optimal crystallization regimes, two settings have been worked out and applied in the present study: the first one, for precise differential thermal analysis and the second one, for the probe method. X-ray fluorescence and X-ray diffraction analysis have allowed accurate determination of iron contents and lattice parameters for synthesized crystals with different $x$. Computer-assisted EPR studies of $\mathrm{Fe}^{3+}$ have revealed a high perfection of the crystals: low degree of disorder and the absence of twinning.
\end{abstract}

\section{Introduction}

Iron borate single-crystal $\mathrm{FeBO}_{3}$, as a model compound, has been used in numerous studies, in particular, in magnetism. This is explained by an extraordinary set of its physical characteristics: magnetic, resonance, magnetoacoustic, optical and magneto-optical, etc., e.g., see [1 15]. A simultaneous occurrence of some of these characteristics is quite outstanding; e.g., $\mathrm{FeBO}_{3}$ is transparent for visible light and, at the same time, magnetically ordered. This crystal has calcite structure, rhombohedral, of $D_{3 d}^{6}$ space group. In the hexagonal system, unit cell parameters are $a=4.626$ and $c=14.493 \AA$, and the unit cell volume is

K. Seleznyova

kira seleznyova@mail.ru

1 Faculty of Physics and Computer Sciences, Crimean Federal University, Simferopol, Russian Federation

2 LOMA, UMR 5798 Université de Bordeaux CNRS, 33405 Talence Cedex, France
$V=268.57 \AA^{3}$ [16]. From the viewpoint of magnetic structure, it is a two sublattice easy-plane antiferromagnet with a weak ferromagnetism, the Néel temperature being $T_{\mathrm{N}}=348 \mathrm{~K}$ [16]. In spite of a great number of studies, the exact nature of certain physical characteristics of this crystal still remains unclear. For instance, magnetic anisotropy (volume and surface $[6,7]$ ) in $\mathrm{FeBO}_{3}$ is known to include two contributions: single-ion anisotropy and magnetic dipole interactions. However, their respective contributions have not yet been reliably evaluated.

Isomorphous substitution of a part of paramagnetic iron in $\mathrm{FeBO}_{3}$ by diamagnetic gallium is a very powerful technique allowing a comprehensive description of various intracrystalline interactions. It makes use of the fact that different mechanisms contributing in the physical characteristics have different concentration and temperature dependences. The series of $\mathrm{Fe}_{x} \mathrm{Ga}_{1-x} \mathrm{BO}_{3}$ single crystals, synthesized in a wide concentration range, allows studying in detail the transformation of various physical characteristics under the transition from magnetically ordered to paramagnetic state.

Iron borate crystals can be synthesized by two routes: (1) from the gas phase and (2) from the solution in the melt. Technology of synthesis of pure iron borate, $\mathrm{FeBO}_{3}$, single crystals by both routes has been developed by our group $[17,18]$. Using the gas-phase technique, we have obtained bulk single crystals of iron borate with large non-basal faces of optical quality. The existence of natural non-basal faces has allowed finding out and describing surface magnetism caused by specific surface anisotropy [6, 7]. Another effect observed only in bulk crystals is magnetic birefringence of sound [4]. The solution in the melt technique allows obtaining thin, $0.050 .1 \mathrm{~mm}$ along the trigonal $\mathrm{C}_{3}$ axis [16] and up to $10 \mathrm{~mm}$ in the basal plane (0001) [16], crystals. These crystals are of high structural 
perfection and much less costly in manufacturing. For the purposes of the present work, this technique has proved to be most appropriate. Thus the solution in the melt technique has been used for isomorphous substitution of $\mathrm{Fe}^{3+}$ by $\mathrm{Ga}^{3+}$ in $\mathrm{Fe}_{x} \mathrm{Ga}_{1-x} \mathrm{BO}_{3}$.

Using the solution-melt technique simplifies the crystal synthesis, allows obtaining materials with complex compositions and reduces the crystallization temperature of refractory compounds. Usually, crystallization regimes suitable for obtaining desired crystal phases are determined empirically, requiring a significant time and financial resources. Hence, express methods of determining the ranges of stability of crystalline phases and temperature borders of the phase formation are desirable. In the present work for this purpose, we have used differential thermal analysis (DTA) and probe method.

After successful $\mathrm{Fe}_{x} \mathrm{Ga}_{1-x} \mathrm{BO}_{3}$ synthesis, a detailed characterization is required for further studies and applications of the samples. The exact crystal composition and parameters of the crystal lattice have been determined by $\mathrm{X}$-ray fluorescence analysis (XRF) and X-ray diffraction (XRD), respectively. Besides, electron paramagnetic resonance (EPR) has been used to estimate local disorder in the $\mathrm{Fe}_{x} \mathrm{Ga}_{1-x} \mathrm{BO}_{3}$ crystals at low $x$ values.

The aim of the present paper is to synthesize series of $\mathrm{Fe}_{x} \mathrm{Ga}_{1-x} \mathrm{BO}_{3}$ crystals in a wide range of substitutions and to obtain their principal characteristics, such as exact crystal composition, parameters of the crystal lattice and quality of the crystals. The synthesized crystals provide the basis for future fundamental magnetic, magneto-optical and resonance studies of the influence of diamagnetic dilution on the properties of the magnetically concentrated iron borate. Besides, from the practical viewpoint, $\mathrm{Fe}_{x-}$ $\mathrm{Ga}_{1-x} \mathrm{BO}_{3}$ crystals are promising for applications as memory elements, magneto-optical and magneto-acoustic transducers, etc., and our developed crystal synthesis technique is well adapted to fine-tuning the characteristics of such materials by varying the concentration of magnetic ions.

\section{Experimental}

$\mathrm{Fe}_{x} \mathrm{Ga}_{1-x} \mathrm{BO}_{3}$ single crystals have been synthesized by solution in the melt technique. Crystallizations were carried out in the $\mathrm{Ga}_{2} \mathrm{O}_{3} \quad \mathrm{Fe}_{2} \mathrm{O}_{3} \quad \mathrm{~B}_{2} \mathrm{O}_{3} \mathrm{PbO} \mathrm{PbF}_{2}$ system. Some examples of charge compositions used in the synthesis are shown in Table 1.

In order to determine exact contents of iron in the synthesized crystals, $x_{\text {crystal }}$, we have carried out XRF analysis.

The parameters of crystal lattice in the series of $\mathrm{Fe}_{x} \mathrm{Ga}_{1-x} \mathrm{BO}_{3}$ crystals have been determined by XRD with
Table 1 Charge compositions used for synthesizing $\mathrm{Fe}_{x} \mathrm{Ga}_{1-x} \mathrm{BO}_{3}$ crystals for some $x$ values

\begin{tabular}{llllll}
\hline$x$ & $\begin{array}{l}\mathrm{Ga}_{2} \mathrm{O}_{3} \\
(\text { Mass \%) }\end{array}$ & $\begin{array}{l}\mathrm{Fe}_{2} \mathrm{O}_{3} \\
(\text { Mass \%) }\end{array}$ & $\begin{array}{l}\mathrm{B}_{2} \mathrm{O}_{3} \\
(\text { Mass \%) }\end{array}$ & $\begin{array}{l}\mathrm{PbO} \\
(\text { Mass \%) }\end{array}$ & $\begin{array}{l}\mathrm{PbF}_{2} \\
(\text { Mass \%) }\end{array}$ \\
\hline 0.02 & 18.52 & 0.08 & & & \\
0.2 & 16.99 & 1.61 & 42.4 & 27.3 & 11.7 \\
0.3 & 14.49 & 4.11 & & & \\
\hline
\end{tabular}

a Rigaku SmartLab diffractometer using copper radiation $\mathrm{CuK} \alpha$ in the angle range of $5^{\circ}<2 \vartheta<100^{\circ}$ with the step of $0.02^{\circ}$.

For estimating the quality of the synthesized crystals, we have chosen EPR characterization technique, particularly sensitive to imperfections of local structure. At low $x$ values, only the EPR of diluted $\mathrm{Fe}^{3+}$ in $\mathrm{GaBO}_{3}$ lattice is observed; therefore, this ion can serve as a high-sensitive probe for evaluating the degree of structural disorder in crystals. A single crystal with $x=0.003$ has been studied by EPR with an X-band Bruker spectrometer at $4 \mathrm{~K}$ and magnetizing fields up to $1 \mathrm{~T}$.

\section{Results and discussion}

DTA can be applied to a wide range of substances; meanwhile, there have been only few DTA studies of the solution-melt systems. This can be explained by the fact that for diluted solutions, sensitivity of this technique is greatly reduced because of the smallness of the exothermic peak on the thermograms [19]. Therefore, we have developed a highly sensitive setting for rapid analysis of small amounts of the solution melts in the temperature range from 300 to $1150{ }^{\circ} \mathrm{C}$. This setting allows detecting weak thermal effects caused by the formation of crystalline phases and determining temperature borders of crystallization with sufficient accuracy [20].

As a differential thermocouple, we have used two platinum crucibles having a volume of $1.5 \mathrm{~cm}^{3}$. This allows recording on the thermograms the temperature difference $\Delta T$ between the crucibles of the order of $0.01{ }^{\circ} \mathrm{C}$.

We have carried out DTA studies of a number of compositions for the crystal synthesis with different concentrations of the components. As an example, the DTA cooling curve for the composition used to synthesize $\mathrm{FeBO}_{3}$ is shown in Fig. 1 (left). As one can see, in the range of $835737{ }^{\circ} \mathrm{C}$, a flat exothermic peak is observed. A detailed analysis of this temperature range has revealed the existence of two exothermic effects, above and below ca. $817{ }^{\circ} \mathrm{C}$, see Fig. 1 (right). The first, at $835817^{\circ} \mathrm{C}$, and the second, at $817737^{\circ} \mathrm{C}$, exothermic effects correspond to the emergence of $\mathrm{Fe}_{3} \mathrm{BO}_{6}$ and $\mathrm{FeBO}_{3}$ phases, respectively. 
Fig. 1 DTA cooling curve for the composition used for the synthesis of $\mathrm{FeBO}_{3}$ in wide temperature range $(l e f t)$ and in a more restricted range of emergence of $\mathrm{FeBO}_{3}$ and $\mathrm{Fe}_{3} \mathrm{BO}_{6}$ phases (right)
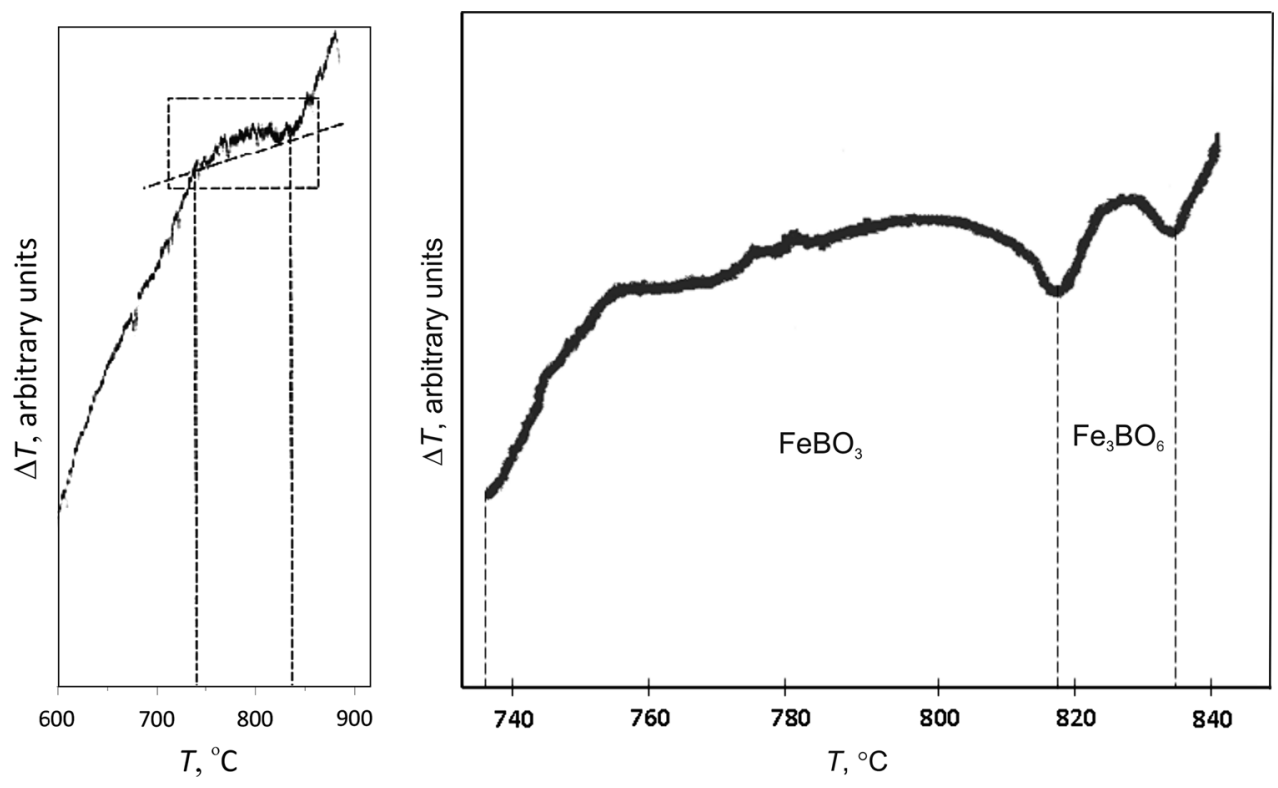

Figure 5 shows the results of XRF analysis; as one can see, $x_{\text {crystal }}$ substantially differs from those in the charge $x_{\text {charge}}$; besides, a considerable difference in iron contents occurs for different crystals extracted from the same crucible. For instance, for $x_{\text {charge }}=0.01, x_{\text {crystal }}$ is in the range from 0.002 to 0.04 .

Figure 6 shows powder XRD patterns for $\mathrm{FeBO}_{3}$ and $\mathrm{Fe}_{0.05} \mathrm{Ga}_{0.95} \mathrm{BO}_{3}$ crystals. In the XRD pattern of pure iron borate $\mathrm{FeBO}_{3}$, we have observed lines at $2 \vartheta=25.43^{\circ}$, $33.38^{\circ \circ}, 37.23^{\circ}, 38.95^{\circ}, 43.39^{\circ}, 47.11^{\circ}, 52.21^{\circ}, 55.09^{\circ}$, $55.78^{\circ}, 61.58^{\circ}, 62.73^{\circ}, 67.04^{\circ}, 70.12^{\circ}, 70.54^{\circ}, 70.72^{\circ}$, $79.31^{\circ}, 82.51^{\circ}, 83.12^{\circ}, 83.65^{\circ}$ and $89.19^{\circ}$, identifiable as corresponding to the planes (012), (104), (006), (110), (113), (202), (024), (116), (018), (211), (122), (214), (208), (300), (119), (0 0 12), (306), (128), (223) and (312) in the hexagonal system [16].

Isomorphous substitution of iron with gallium produces a change of the lattice parameters manifesting itself in a shift of the XRD peaks from their positions in pure iron borate, see Fig. 6. The hexagonal lattice parameters $a$ and $c$ can be calculated using the following expression [21]:

$\frac{1}{d^{2}}=\frac{4}{3} \frac{h^{2}+h k+k^{2}}{a^{2}}+\frac{l^{2}}{c^{2}}$

where $d$ is the interplanar spacing calculated using the Bragg's formula $d=\lambda / 2 \sin \vartheta$, and $h, k$ and $l$ represent the lattice planes.

The lattice parameters in $\mathrm{Fe}_{x} \mathrm{Ga}_{1-x} \mathrm{BO}_{3}$ crystals have been calculated using the positions of the most "convenient" peaks, e.g., (300) for $a$ and (006) and (0 0 12) for $c$. Next, these parameters have been refined by graphical extrapolation for all diffraction peaks in the angle range of gradually modified with the iron contents, from almost transparent to green and dark green. 


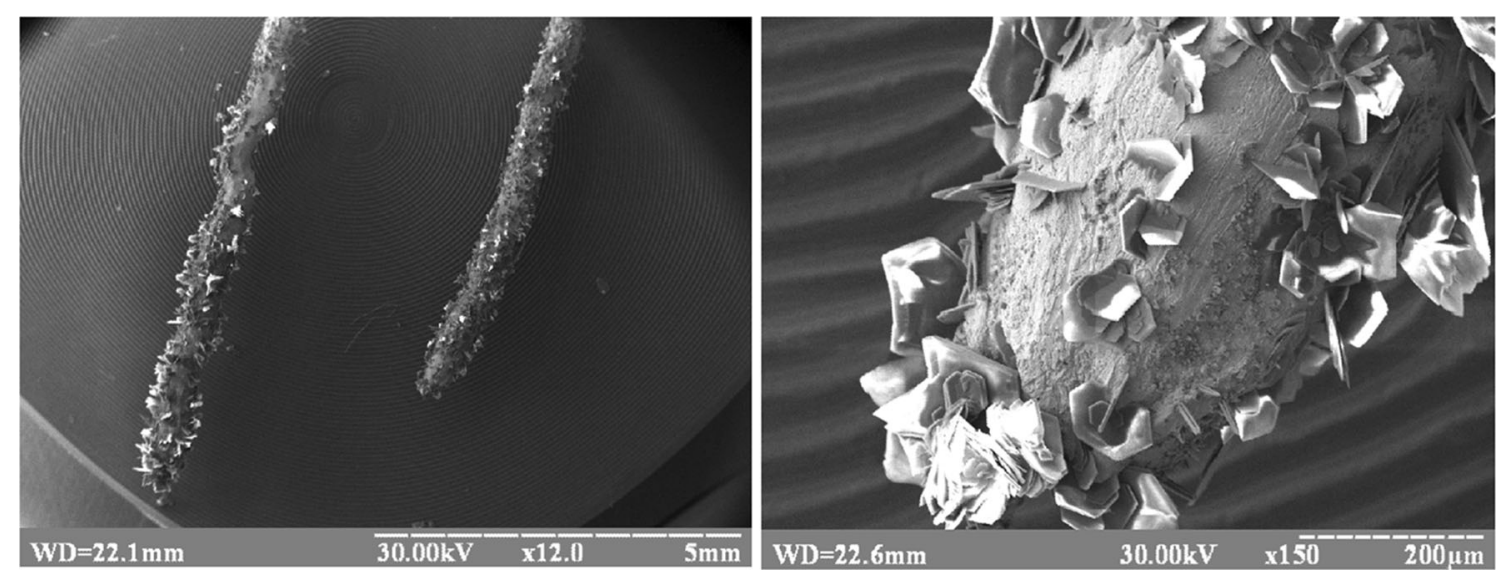

Fig. 2 Electron microscope pictures showing $\mathrm{FeBO}_{3}$ single crystals on the probes for two different magnifications

Fig. 3 Temperature mode of crystallization used in synthesizing $\mathrm{Fe}_{x} \mathrm{Ga}_{1-x} \mathrm{BO}_{3}$ crystals of a definite composition

Fig. $4 \mathrm{Fe}_{x} \mathrm{Ga}_{1-x} \mathrm{BO}_{3}$ single crystals with different $x$ (left) and $\mathrm{GaBO}_{3}$ crystals on the seed holder (right)
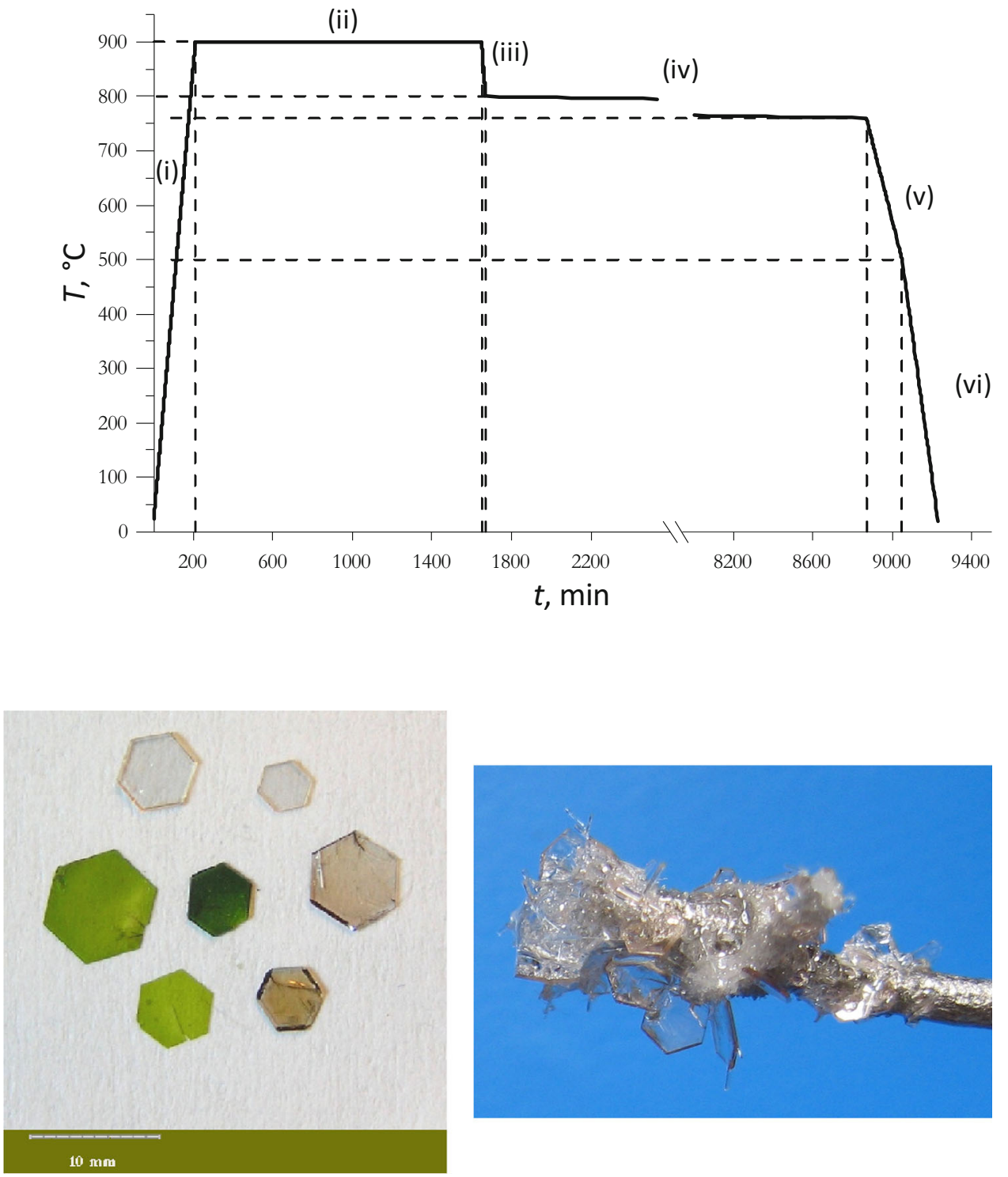
$40^{\circ}<2 \vartheta<100^{\circ}$. The dependences of $a$ and $c$ on the crystal composition are shown in Fig. 7.

According to the Vegard's law [22], suggesting a linear relationship between the lattice parameters of a solid solution and concentrations of its constituent components,

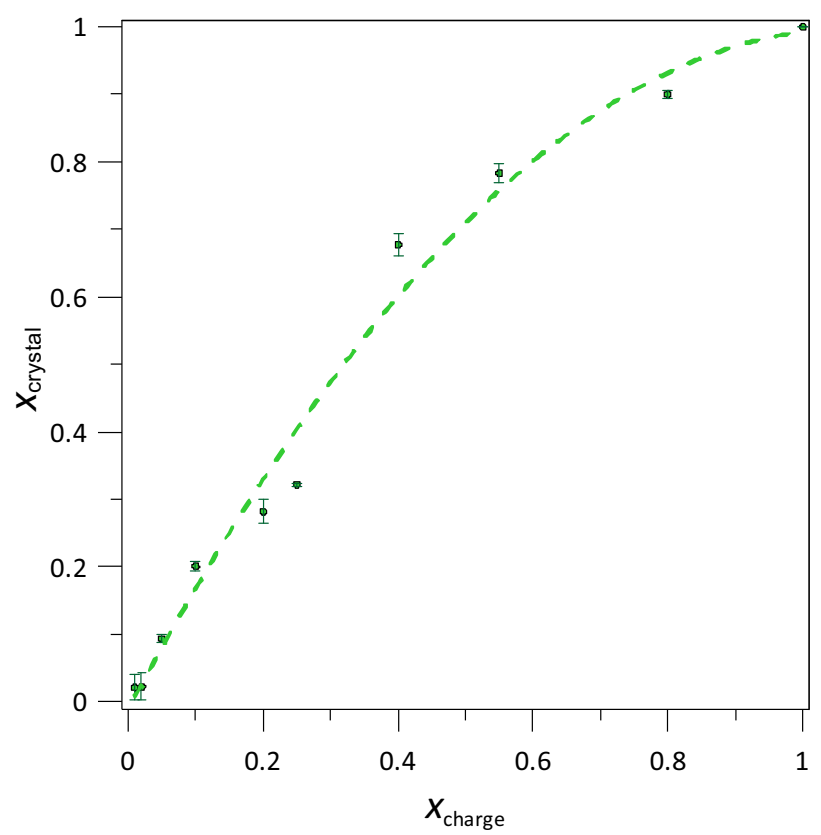

Fig. 5 Iron contents in $\mathrm{Fe}_{x} \mathrm{Ga}_{1-x} \mathrm{BO}_{3}$ crystals extracted from one and the same crucible versus initial iron contents in the charge. The dashed line is a guide for the eyes the following relation should hold for $\mathrm{Fe}_{x} \mathrm{Ga}_{1-x} \mathrm{BO}_{3}$ crystals:

$$
\begin{aligned}
& a_{\mathrm{Fe}_{x} \mathrm{Ga}_{1}{ }_{x} \mathrm{BO}_{3}}=x_{\text {crystal }} a_{\mathrm{FeBO}_{3}}+\left(1-x_{\text {crystal }}\right) a_{\mathrm{GaBO}_{3}}, \\
& c_{\mathrm{Fe}_{x} \mathrm{Ga}_{1}{ }_{x} \mathrm{BO}_{3}}=x_{\text {crystal }} c_{\mathrm{FeBO}_{3}}+\left(1-x_{\text {crystal }}\right) c_{\mathrm{GaBO}_{3}} .
\end{aligned}
$$

The dashed lines in Fig. 7 are obtained by least square fitting of the experimental data to this relation. One can see that in the limits of errors, this relation quite adequately describes the experimental tendencies.

The experimental EPR spectrum, curve a in Fig. 8, is typical of isolated $\mathrm{Fe}^{3+}$ in oxygen environment in the case where the Zeeman interaction is comparable with the quadrupole fine structure. The spin Hamiltonian parameters have been determined by computer simulating the EPR spectra with laboratory-made code based on a generalized spin Hamiltonian [23]. Besides, no structurally nonequivalent iron sites have been detected, proving the absence of twinning in the crystals.

In the presence of certain local disorder in the crystals, all coordinates of the atoms surrounding the paramagnetic ions undergo random site-to-site distributions. Consequently, the spin Hamiltonian parameters also are distributed, resulting in broadening of certain resonance lines and concomitant decrease in their amplitudes. To estimate the degree of local disorder, we have put forward a simulation code on the basis of the general spin Hamiltonian expressed by means of tesseral spherical tensor operators $\mathscr{T}_{l m}^{l_{B} l_{S}}(\boldsymbol{n}, \boldsymbol{S})\left[\begin{array}{ll}23 & 26\end{array}\right]:$
Fig. 6 XRD patterns of $\mathrm{FeBO}_{3}$ (bottom curve) and $\mathrm{Fe}_{0.05} \mathrm{Ga}_{0.95} \mathrm{O}_{3}$ (top curve)

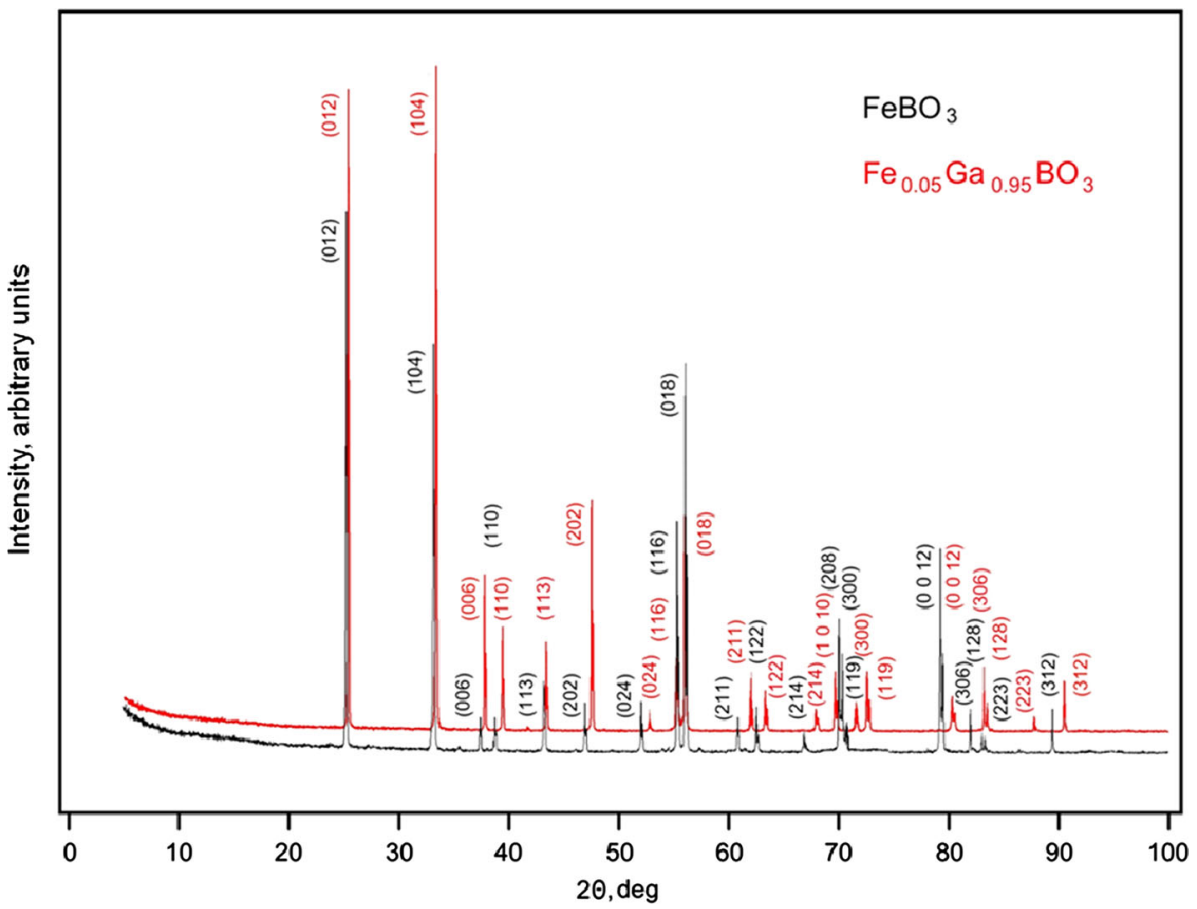



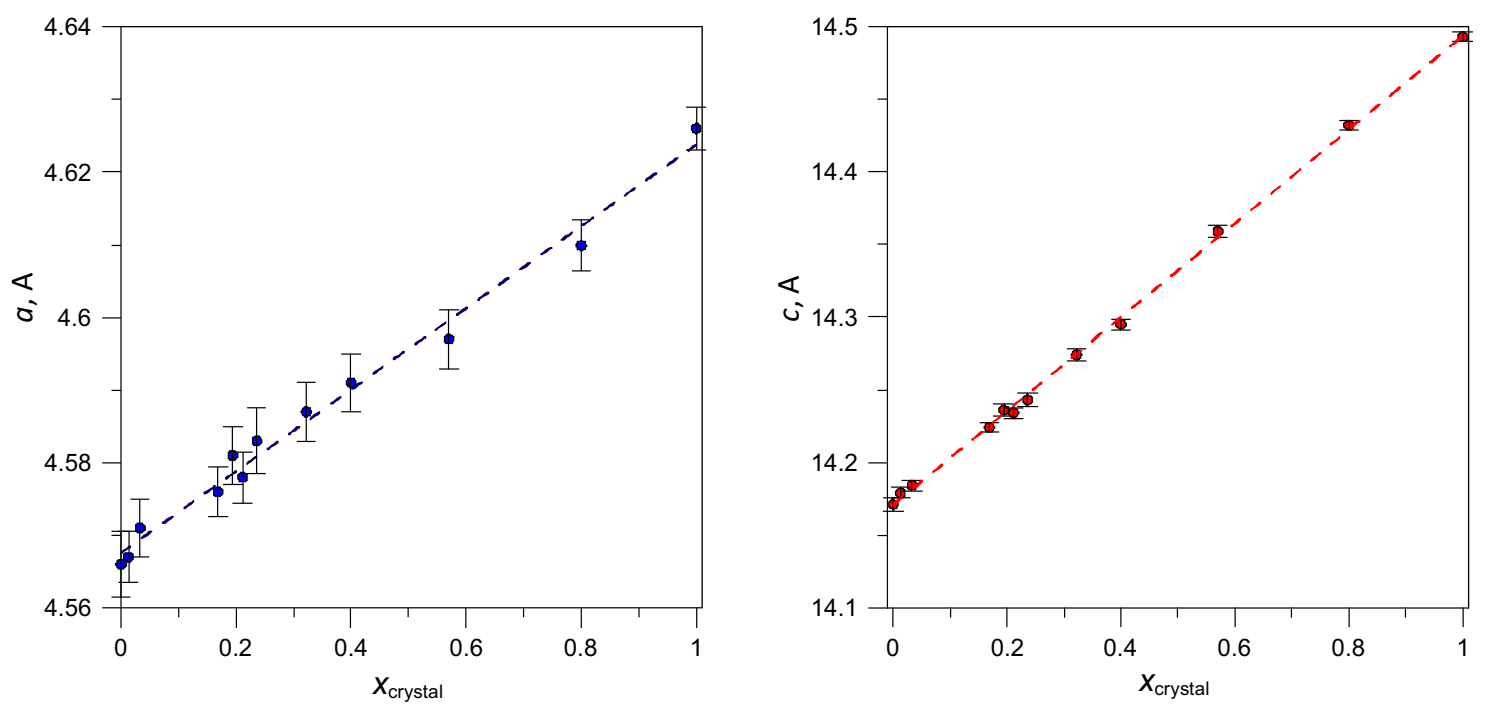

Fig. 7 Concentration dependences of lattice parameters $a$ (left) and $c$ (right). Dashed lines indicate least square fittings

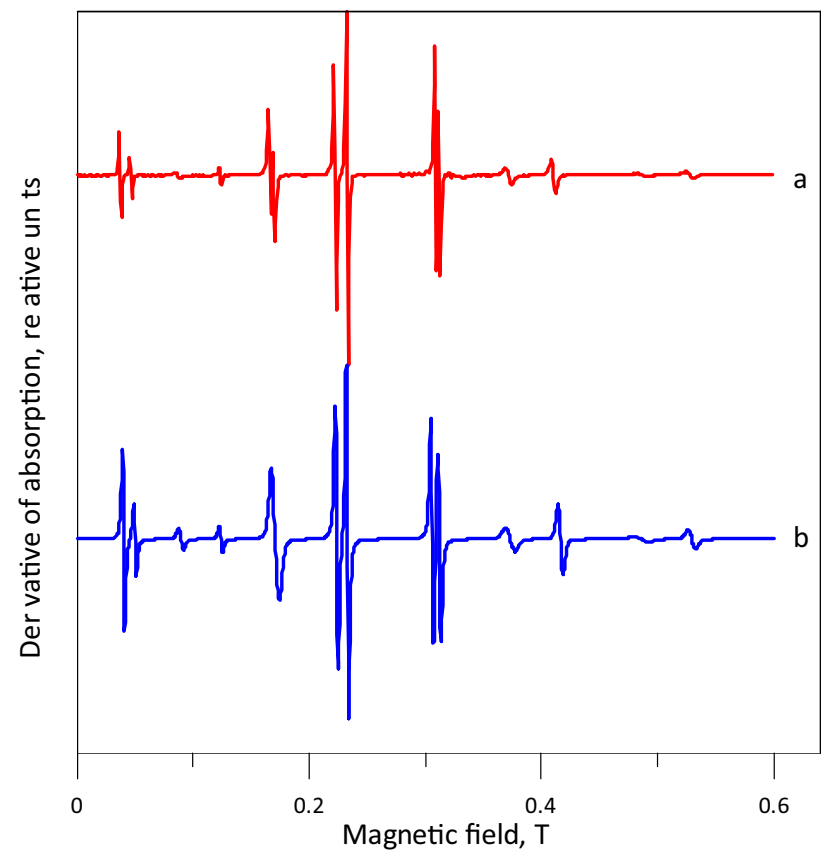

Fig. 8 Experimental (a) and computer generated (b) EPR spectra. The simulation has been made with $\sigma \quad 0.0003 \AA$

$$
\begin{aligned}
\mathscr{H}= & \sum_{l=2,4} \sum_{m=l}^{l} \mathscr{B}_{l m}^{0 l} \mathscr{T}_{l m}(\boldsymbol{S}) \\
& +g_{\mathrm{e}} \beta B \sum_{l_{S}=1,3,5} \sum_{l=\left\{\begin{array}{l}
l_{S} 1 \\
l_{S}+1
\end{array}\right.} \sum_{m=l}^{l} \mathscr{B}_{l m}^{1 l_{S}} \mathscr{T}_{l m}^{1 l_{S}}(\boldsymbol{n}, \boldsymbol{S})
\end{aligned}
$$

where the first and second terms on the right-hand side are, respectively, zero-field and linear Zeeman spin Hamiltonians; the $\mathscr{B}_{l m}^{0 l}$ parameters are proportional to the corresponding Stevens parameters $B_{l}^{m}$ [24], $\beta$ is the Bohr magneton, $\boldsymbol{n}$ is the unit vector of the magnetizing field $\boldsymbol{B}, \boldsymbol{S}$ is the electron spin, and $g_{\mathrm{e}}$ is the free electron $g$-factor.

The advantage of using the spin Hamiltonian (3) is that it allows explicitly relating the disorder-caused distributions of atomic positions with those of the spin Hamiltonian parameters. As far as $\mathscr{B}_{l m}^{l_{B} l_{S}}$ are components of irreducible tensors of rank $l$ [24], they can be consistently expressed through the superposition model [27], as follows, for details, see $[25,26]$ :

$\mathscr{B}_{l m}^{l_{B} l_{S}}=\sum_{j=1}^{n} \bar{b}_{l m}^{l_{B} l_{S}}\left(r_{j}\right) C_{l}^{m}\left(\vartheta_{j}, \varphi_{j}\right)$

where $j$ enumerates the nearest neighbors of the paramagnetic ion (ligands) with spherical coordinates $r_{j}, \vartheta_{j}$ and $\varphi_{j}$ and $C_{l}^{m}\left(\vartheta_{j}, \varphi_{j}\right)$ are tesseral coordination factors. For simplicity, we assume that the radial functions $\bar{b}_{l m}^{l_{B} l_{S}}\left(r_{j}\right)$ depend only on $l_{B}$ and $l_{S}$ and have the radial dependence given by the relation $\bar{b}_{l m}^{l_{B} l_{S}}\left(r_{j}\right)=\bar{b}_{l_{B} l_{S}} \times\left(r_{0} / r_{j}\right)^{t_{B} l_{S}}$, with the intrinsic parameters $\bar{b}_{l_{B} l_{S}}$ and power exponents $t_{l_{B} l_{S}}$ considered as fitting parameters.

In order to numerically estimate the amount of local disorder, we have attributed different normal random siteto-site distributions to the Cartesian coordinates of $\mathrm{Fe}^{3+}$ ligands, and we have calculated the parameter distributions of the spin Hamiltonian (3) by means of the superposition model. Figure 9 shows computer simulations of a chosen EPR line, for different amounts of local disorder estimated from the width, $\sigma$ of the distributions of the ligand coordinates. As one can see, with increasing the disorder, the width of this line drastically increases, and its amplitude decreases, so that the integrated line intensity remains 


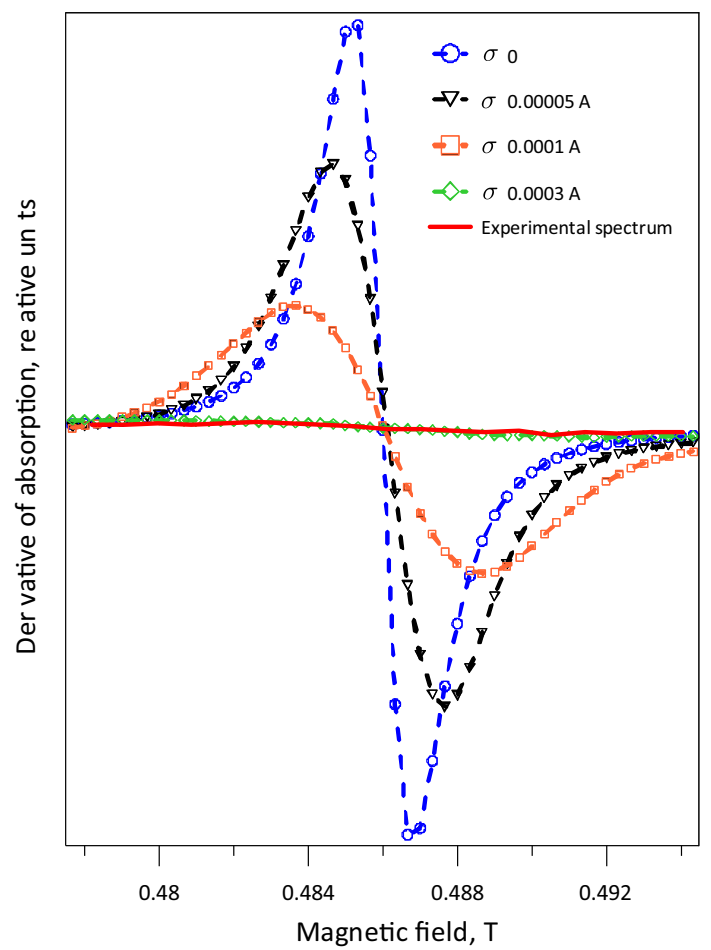

Fig. 9 Experimental EPR line at ca. $0.486 \mathrm{~T}$ and the corresponding part of computer generated spectrum with different distribution widths of the ligand coordinates

roughly the same. The best agreement between the experimental and computer-generated line profile is attained at $\sigma \approx 0.0003 \AA$. Besides, Fig. 8 shows that with such parameter distributions, a good fitting, curve $b$, is achieved for the whole experimental spectrum.

\section{Conclusions}

We have succeeded in obtaining high-quality $\mathrm{Fe}_{x} \mathrm{Ga}_{1-x} \mathrm{BO}_{3}$ single crystals in the whole range of concentrations, using the solution in the melt technique for isomorphous substitution in iron-gallium borate system. By means of differential thermal analysis and the probe method, we have determined the component ratios in the charge and the corresponding temperature modes optimal for the crystal synthesis for different $x$.

The XRF analysis has revealed a certain dispersion of the contents of $\mathrm{Fe}^{3+}$ and $\mathrm{Ga}^{3+}$ ions in the crystals extracted from the same crucible. The XRD analysis has shown that diamagnetic dilution modifies the parameters of crystal lattice of gallium borate according to the Vegard's law.

The EPR studies have allowed evaluating the degree of local disorder, and its value (the distribution width of atom coordinates estimated as $\sigma \approx 0.0003 \AA$ ) confirms a high quality of the crystals.
Acknowledgments This work was partially supported by Russian Foundation for Basic Research, Grant No. 144201557.

\section{References}

1. D. Afanasiev, I. Razdolski, K.M. Skibinsky, D. Bolotin, S.V. Yagupov, M.B. Strugatsky, A. Kirilyuk, Th. Rasing, A.V. Kimel, Phys. Rev. Lett. 112, 147403 (2014)

2. M. Eibshutz, M.E. Lines, Phys. Rev. B 7, 4907 (1973)

3. A.M. Kalashnikova, A.V. Kimel, R.V. Pisarev, V.N. Gridnev, P.A. Usachev, A. Kirilyuk, Th. Rasing, Phys. Rev. B 78, 104301 (2008)

4. Yu.N. Mitsay, K.M. Skibinsky, M.B. Strugatsky, A.P. Korolyuk, V.V. Tarakanov, V.I. Khizhnyi, JMMM 219, 340 (2000)

5. K. Parlinski, J. Łaźewski, P.T. Jochym, A. Chumakov, R. Rüffer, G. Kresse, Europhys. Lett. 56, 275 (2001)

6. V.E. Zubov, G.S. Krinchik, V.N. Seleznyov, M.B. Strugatsky, JMMM 86, 105 (1990)

7. E.M. Maksimova, I.A. Nauhatsky, M.B. Strugatsky, V.E. Zubov, JMMM 322, 477 (2010)

8. L.V. Velikov, A.S. Prokhorov, E.G. Rudawevskii, V.N. Seleznev, JETP 66, 1847 (1974)

9. M.B. Strugatsky, K.M. Skibinsky, V.V. Tarakanov, V.I. Khizh nyi, JMMM 241, 330 (2002)

10. M.B. Strugatsky, K.M. Skibinsky, JMMM 309, 64 (2007)

11. I.A. Troyan, M.I. Eremets, A.G. Gavrilyuk, I.S. Lyubutin, V.A. Sarkisyan, JETP Lett. 78, 13 (2003)

12. A.M. Kalashnikova, A.V. Kimel, R.V. Pisarev, V.N. Gridnev, P.A. Usachev, A. Kirilyuk, Th. Rasing, Phys. Rev. Lett. 99, 167205 (2007)

13. K. Egashira, T. Manabe, H. Katsuraki, J. Phys. Soc. Jpn. 31, 602 (1971)

14. A.V. Malakhovskii, I.S. Edelman, Phys. Status Solidi (b) 74, K145 (1976)

15. W. Jantz, J.R. Sandercock, W. Wettling, J. Phys. C 9, 2229 (1976)

16. R. Diehl, W. Jantz, B.I. Nolang, W. Wettling, Growth and properties of iron borate, $\mathrm{FeBO}_{3}$, in Current Topics in Materials Science, vol. 11, ed. by E. Kaldis (Elsevier, New York, 1984), pp. 241387

17. A.K. Pankratov, M.B. Strugatsky, S.V. Yagupov, Sci. Notes of Taurida National University, Ser. Phys., 20(59), 64 (2007)

18. M.B. Strugatsky, S.V. Yagupov, Sci. Notes of Taurida National University, Ser. Phys., 19(58), 76 (2006)

19. V.A. Timofeeva, Crystal Growth from the Solution in the Melt (Nauka, Moscow, 1978). (in Russian)

20. S.V. Yagupov, M.B. Strugatsky, N.S. Postivey, S.S. Kostulin, Sci. Notes of Taurida National University, Ser. Phys. Math. 23(62), 121 (2010)

21. H. Lipson, H. Stipl, Interpretation of the Powder X ray Patterns (Macmillan, St. Martins Press, London, New York, 1970)

22. L. Vegard, Z. Phys. 5(1), 17 (1921)

23. K. Seleznyova, M. Strugatsky, S. Yagupov, N. Postivei, A. Artemenko, J. Kliava, Phys. Status Solidi B 251, 1393 (2014)

24. D.G. McGavin, W.C. Tennant, J.A. Weil, J. Magn. Reson. 87, 92 (1990)

25. J. Kliava, R. Berger, in 16ème Colloque Internat. OHD 2001, Le Mans (2001), p. 53

26. J. Kliava, R. Berger, in Recent Res. Devel. Non Crystalline Solids 3, Transworld Research Network, ISBN 817895090141 (2003)

27. J. Newman, W. Urban, J. Phys. C5, 3101 (1972) 